\title{
Correction to: Differential neurovirulence of Usutu viruslineages in mice and neuronal cells
}

\author{
Marion Clé ${ }^{\dagger}$, Orianne Constant ${ }^{1 \dagger}$, Jonathan Barthelemy ${ }^{1}$, Caroline Desmetz ${ }^{2}$, Marie France Martin ${ }^{3}$, Lina Lapeyre ${ }^{3}$, \\ Daniel Cadar ${ }^{4}$, Giovanni Savini ${ }^{5}$, Liana Teodori ${ }^{5}$, Federica Monaco ${ }^{5}$, Jonas Schmidt-Chanasit ${ }^{4,6}$, Juan-Carlos Saiz ${ }^{7}$, \\ Gaëlle Gonzales ${ }^{8}$, Sylvie Lecollinet ${ }^{8}$, Cécile Beck ${ }^{8}$, Fabien Gosselet ${ }^{9}$, Philippe Van de Perre ${ }^{1,10}$, \\ Vincent Foulongne ${ }^{1,10}$, Sara Salinas ${ }^{1}$ and Yannick Simonin ${ }^{1 *}$
}

\section{Correction to: J Neuroinflammation (2021) 18:11 https://doi.org/10.1186/s12974-020-02060-4}

Following publication of the original article [1], the authors noticed that there were error bars offset in Figs. 3,5 and 6 in the published version of this article. Presented here are the corrected Figs. 3, 5 and 6. The original article has been updated.

\section{Author details}

${ }^{1}$ Pathogenesis and Control of Chronic Infections, Université de Montpellier,INSERM, EFS, Montpellier, France. ${ }^{2}$ BioCommunication en CardioMétabolique(BC2M), Montpellier University, Montpellier, France. ${ }^{3}$ Université deMontpellier, CNRS, Viral Trafficking, Restriction and Innate Signaling, Montpellier, France. ${ }^{4}$ Bernhard Nocht Institute for Tropical Medicine, WHO Collaborating Centre for Arbovirus and Haemorrhagic Fever Reference and Research, 20359 Hamburg, Germany. ${ }^{5}$ OIE Reference Centre for West NileDisease, Istituto Zooprofilattico Sperimentale"G. Caporale", 46100 Teramo, Italy. ${ }^{6}$ Faculty of Mathematics, Informatics and Natural Sciences, UniversitätHamburg, 20148 Hamburg, Germany. 'Department of Biotechnology, INIA, Madrid, Spain. ${ }^{8}$ UPE, Anses Animal Health Laboratory, UMR1161 Virology, INRA, Anses, ENVA, Maisons-Alfort, France. ${ }^{9}$ Blood-Brain Barrier Laboratory (BBB Lab), University of Artois, UR2465, F-62300 Lens, France. ${ }^{10}$ Centre Hospitalier Universitaire de Montpellier, Montpellier, France.
Published online: 23 February 2021

Reference

1. Clé M, Constant O, Barthelemy J, et al. Differential neurovirulence of Usutu virus lineages in mice and neuronal cells. J Neuroinflammation. 2021;18:11 https://doi.org/10.1186/s12974-020-02060-4.

The original article can be found online at https://doi.org/10.1186/s12974 020-02060-4.

*Correspondence: yannick.simonin@umontpellier.fr

${ }^{\dagger}$ Marion Clé and Orianne Constant contributed equally to this work.

'Pathogenesis and Control of Chronic Infections, Université de Montpellier,INSERM, EFS, Montpellier, France

Full list of author information is available at the end of the article

(c) The Author(s). 2021 Open Access This article is licensed under a Creative Commons Attribution 4.0 International License, which permits use, sharing, adaptation, distribution and reproduction in any medium or format, as long as you give appropriate credit to the original author(s) and the source, provide a link to the Creative Commons licence, and indicate if changes were made. The images or other third party material in this article are included in the article's Creative Commons licence, unless indicated otherwise in a credit line to the material. If material is not included in the article's Creative Commons licence and your intended use is not permitted by statutory regulation or exceeds the permitted use, you will need to obtain permission directly from the copyright holder. To view a copy of this licence, visit http://creativecommons.org/licenses/by/4.0/. The Creative Commons Public Domain Dedication waiver (http://creativecommons.org/publicdomain/zero/1.0/) applies to the data made available in this article, unless otherwise stated in a credit line to the data. 
A
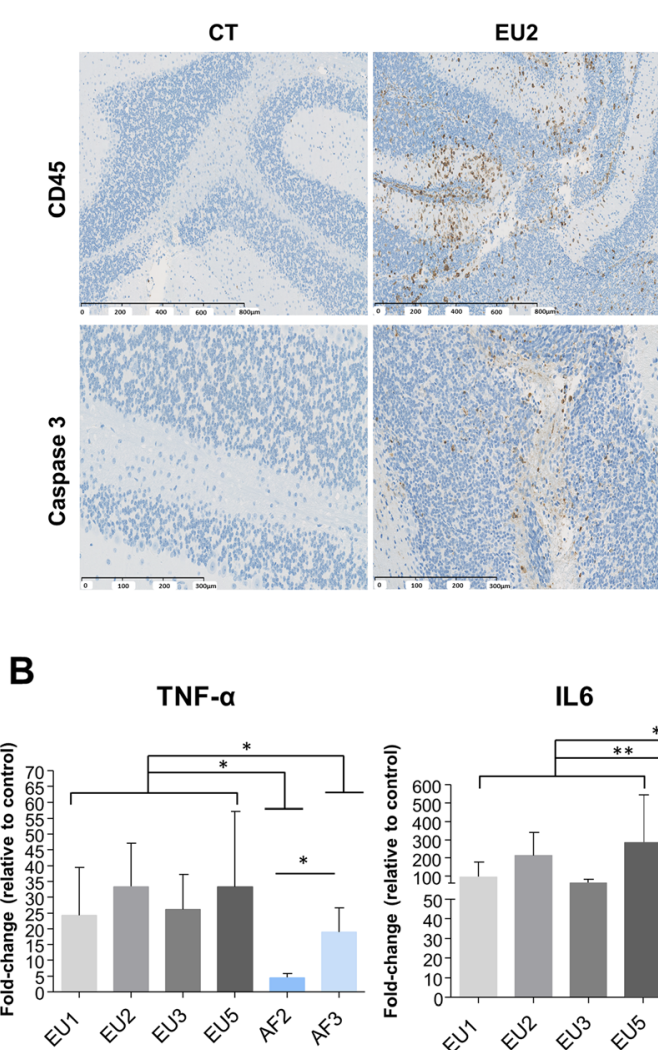

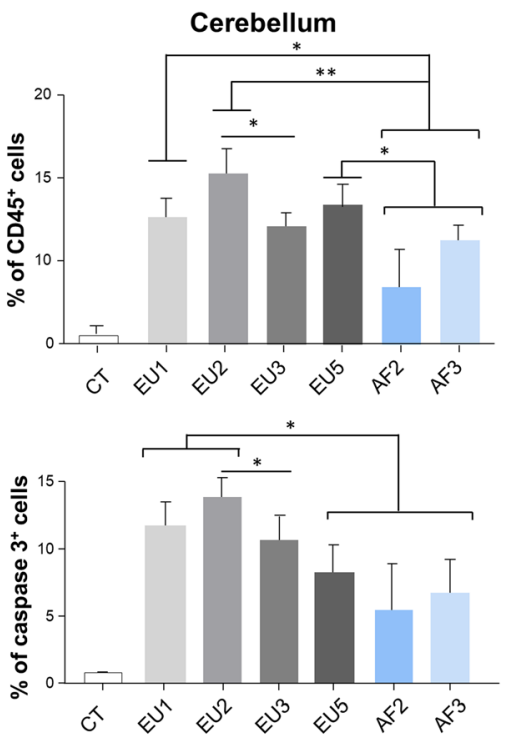

IFN- $\boldsymbol{\beta}$
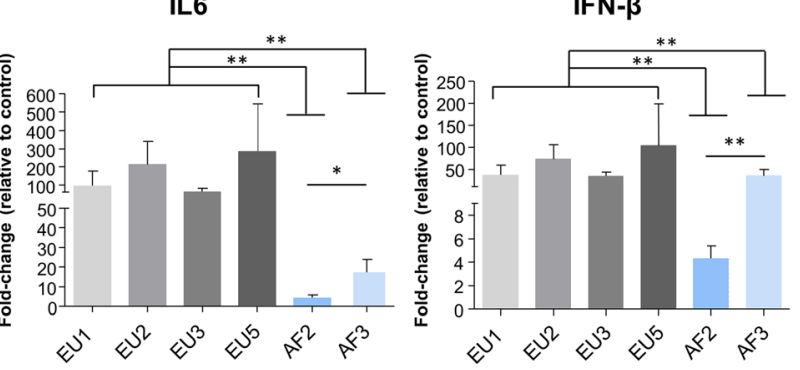

IL1 $\beta$

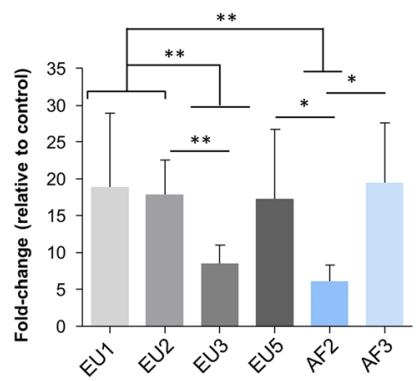

Fig. 3 USUV isolates differentially induce cellular infiltration, apoptosis, and inflammation in the mice brain. a Left panel: Immunohistochemical CD45 staining (associated with luxol blue) showing inflammatory infiltrates in the infected brain (brown staining) at 6 dpi. Some cells present caspase 3 staining after immunohistochemistry. Right panel: Quantification of CD45-positive cells and caspase 3 positive cells in USUV-infected brain compared to CT. $\mathbf{b}$ qRT-PCR analysis of TNFa, IL6, IFN $\beta$, and IL $1 \beta$ mRNA from the brain collected at 6 dpi. Each histogram represents the mean \pm SEM from 6 independent mice normalized to $C T$. ${ }^{*} p<0.05$ and ${ }^{* *} p<0.01$ 


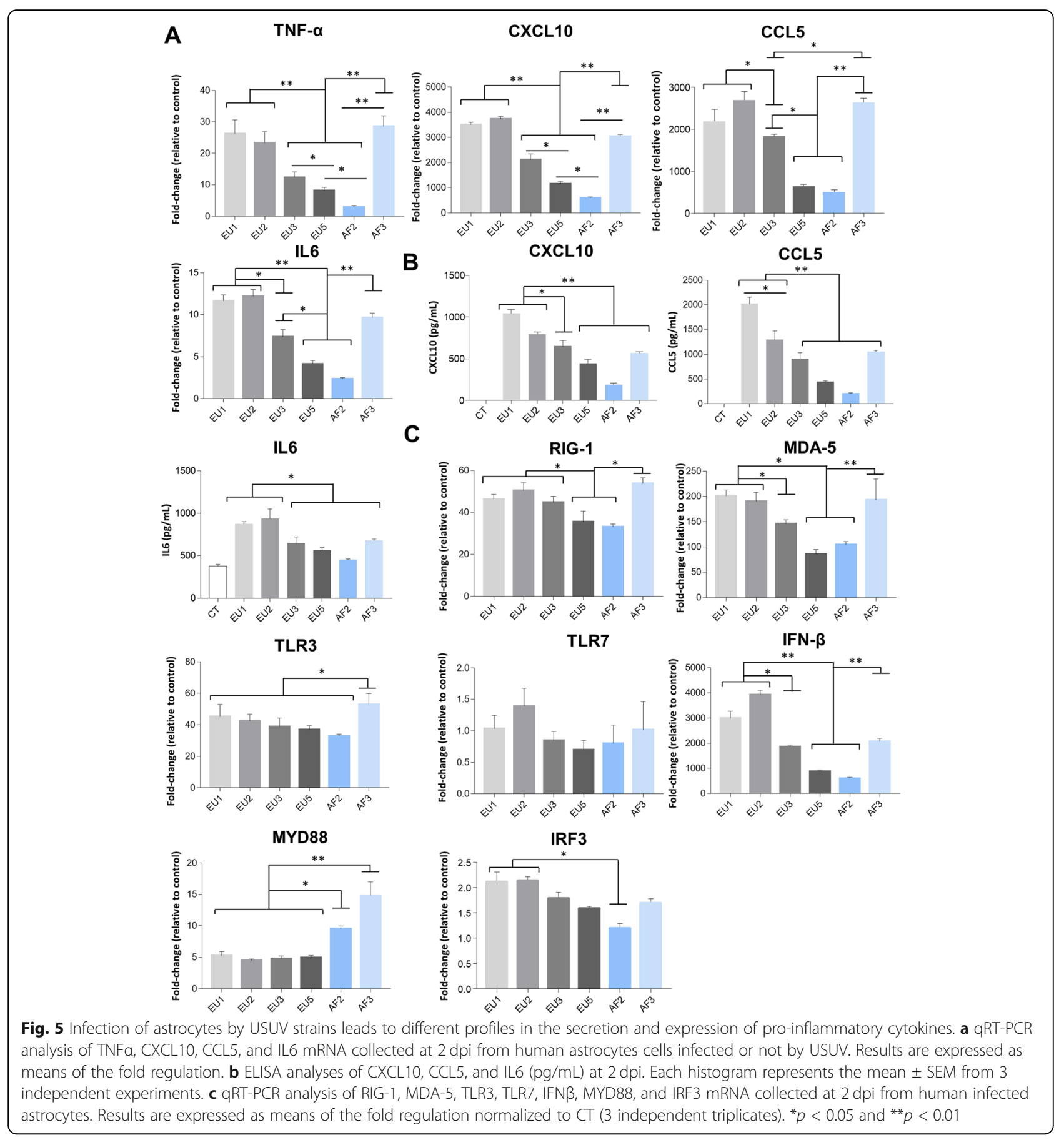


A

$5 \mathrm{dpi}$

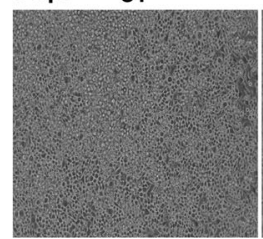

EU2

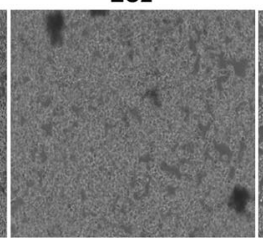

AF3

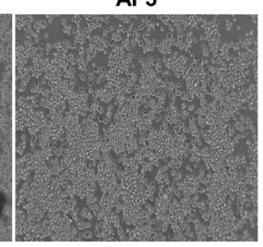

B

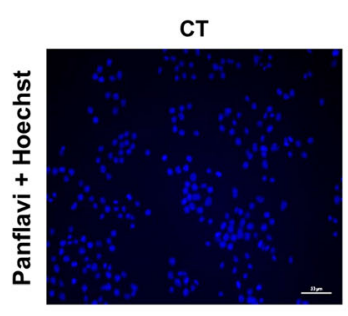

C

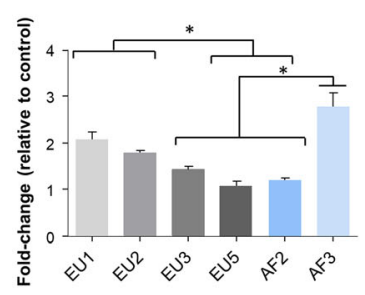

IL6

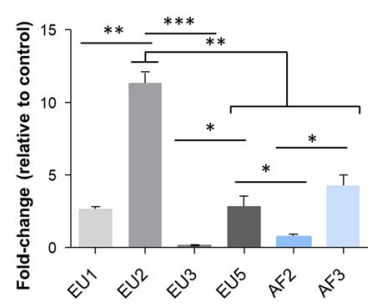

CXCL10

IFN- $\boldsymbol{\beta}$
- EU $1-\mathrm{EU}_{3}-\mathrm{AF} 2$
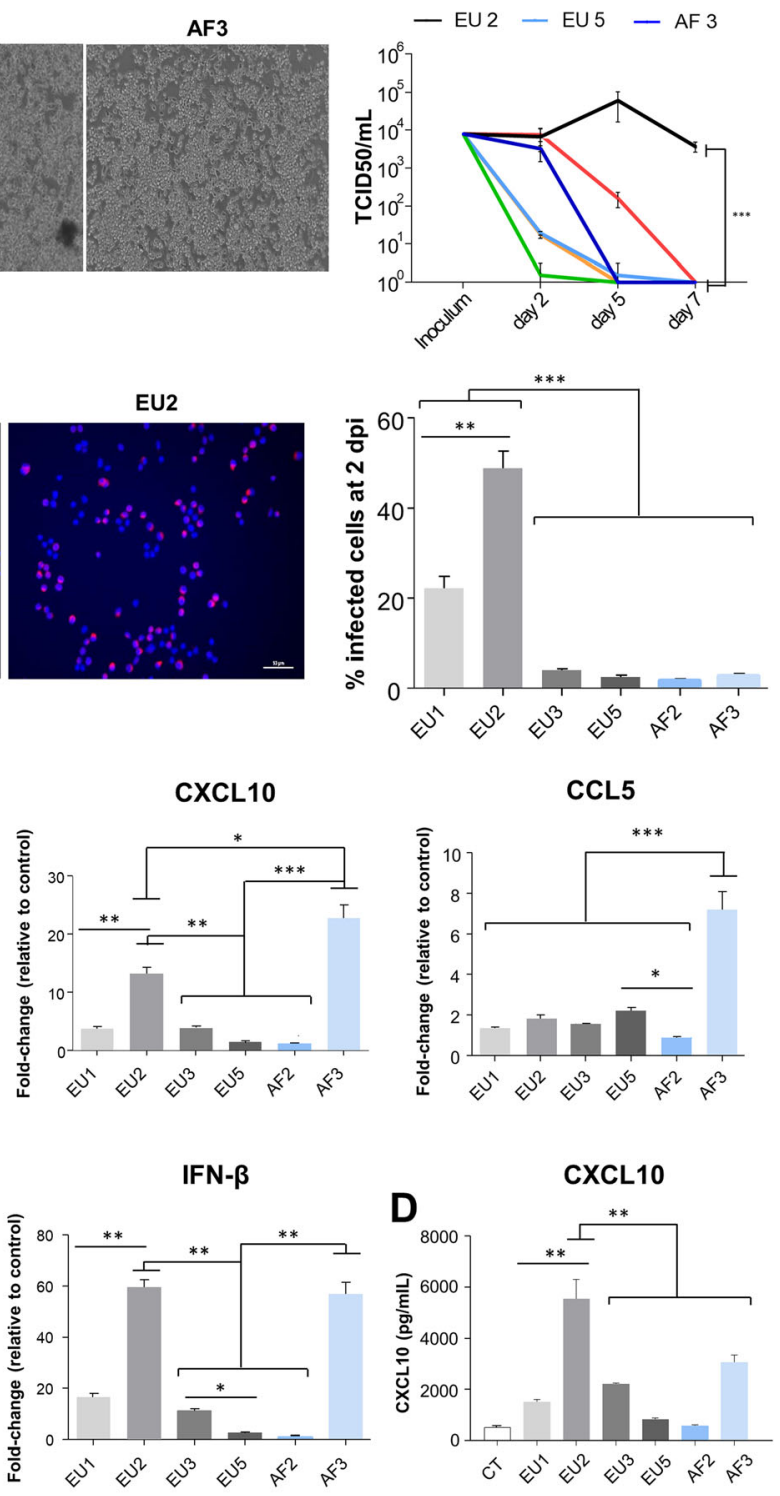

CXCL10

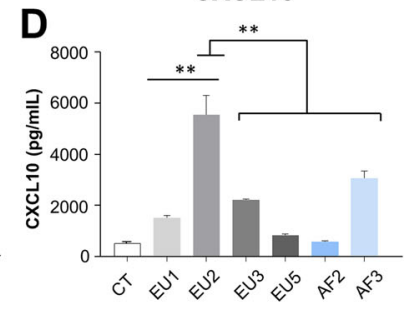

Figure 6

Fig. 6 USUV strains replicate differentially in murine microglia and EU2 strains persist longer. Murine microglia were infected with USUV strains at a MOI of 0.1. a Left panel: Bright light images of control and USUV-infected microglia at 5 dpi. We observe an atypical CPE- in EU2-infected cells. Right panel: Supernatants from infected cells (MOI 0.1) were collected at 2, 5, and $7 \mathrm{dpi}$, and subjected to TCID50 measurement. Viral production in USUV-infected microglia shows difference in terms of replication and persistence between strains, with greater virulence for EU2. b Left panel: USUV-infected cells were fixed at $2 \mathrm{dpi}$ and labeled with the pan-flavivirus antibody (in red) as showed for EU2 strain. Scale bar $=50 \mu \mathrm{m}$. The corresponding quantification is indicated on the right panel ( $n=3$ independent experiments). c RT-qPCR analysis of TNFa, CXCL10, CCL5, IL6, and IFN $\beta$ of mRNA collected at $2 \mathrm{dpi}$ from infected and non-infected (CT) microglial cells. $\mathbf{d}$ Analyses of CXCL10 by ELISA in the supernatants of CT- or USUV-infected microglia at 2 dpi. Results are expressed as mean \pm SEM. ${ }^{*} p<0.05,{ }^{* *} p<0.01$, and ${ }^{* * *} p<0.001$ 